\title{
Effectiveness of 23-valent pneumococcal polysaccharide vaccine in adults aged 60 years and over in the Region of Madrid, Spain, 2008-2011
}

M A Gutiérrez Rodríguez (angeles.gutierrez@salud.madrid.org)1, M A Ordobás Gavín ${ }^{1}$, L García-Comas ${ }^{1}$, J C Sanz Moreno²,

E Córdoba Deorador ${ }^{1}$, M D Lasheras Carbajo ${ }^{1}$, J A Taveira Jiménez ${ }^{1}$, F Martín Martínez ${ }^{1}$, D Iniesta Fornies ${ }^{1}$, A Arce Arnaez ${ }^{1}$

1. Dirección General de Atención Primaria, Subdirección de Promoción de la Salud y Prevención, Consejería de Sanidad, Comunidad de Madrid, Spain

2. Dirección General de Ordenación e Inspección, Laboratorio Regional de Salud Pública, Consejería de Sanidad, Comunidad de Madrid, Spain

Gutiérrez Rodríguez MA, Ordobás Gavín MA, García-Comas L, Sanz Moreno JC, Córdoba Deorador E, Lasheras Carbajo MD, Taveira Jiménez JA, Martín Martínez F, Iniesta Fornies D, Arce Arnaez A. Effectiveness of 23 -valent pneumococcal polysaccharide vaccine in adults aged 60 years and over in the Region of Madrid, Spain,

2008-2011. Euro Surveill. 2014;19(40):pii=20922. Available online: http://www.eurosurveillance.org/ViewArticle.aspx?Articleld=20922

Invasive pneumococcal disease (IPD) is a notifiable disease in the Region of Madrid. The 23-valent pneumococcal polysaccharide vaccine (PPV23) is recommended for children and adults aged two years or over with a high risk of disease, and for all adults aged 60 and over. We describe the evolution of IPD incidence from 2008 to 2011 in people aged 60 years and over and PPV23 vaccine effectiveness (VE). VE is estimated using both the screening method and indirect cohort method. The incidence of IPD varied from 20.0 in 2008 to 15.2 per 100,000 inhabitants in 2011 (RR: 0.8; $95 \%$ $\mathrm{Cl}$ : 0.6-0.9). Adjusted VE estimated with the screening method was $68.2 \%$ ( $95 \% \mathrm{Cl}: 56.2-76.9)$. VE with the Broome method was $44.5 \%$ (95\% Cl: 23.8-59.6) for all PPV23 serotypes, and $64.4 \%$ (95\% Cl: 45.2-76.8) for PPV23 serotypes not included in conjugate vaccines. VE was lower in patients aged 80 years and older (25.5\%; 95\% Cl:-23.2 to 55.0) and those with highrisk medical conditions (31.7\%; 95\% Cl: -2.2 to -54.4 ). Adjusted VE was $44.5 \%$ (95\% Cl: 19.4-61.8) within 5 years of vaccination and $32.5 \%(95 \% \mathrm{Cl}:-5.6$ to 56.9$)$ after 5 years. These results are compatible with current recommendations for PPV23.

\section{Introduction}

Pneumococcal disease has high morbidity and mortality rates worldwide, mainly in children and in the elderly. The fatality rates for pneumococcal bacteraemia can reach $15-20 \%$ in adults and $30-40 \%$ in the elderly [1]. The incidence of invasive pneumococcal disease (IPD) is highly variable according to geographical region, ranging from 8 to 34 cases per 100,000 inhabitants [2].

The human nasopharynx is the natural ecosystem for Streptococcus pneumoniae. Young children are the main reservoir. The prevalence of carriers ranges from $27 \%$ in developed countries to $85 \%$ in developing ones
[1]. Many conditions and behaviours that alter the host's immunological capacity pave the way for a predisposition to the disease, including alcoholism, cigarette smoking, chronic lung disease, congestive heart failure, diabetes mellitus, malignant neoplasm, renal disease, liver disease, immunosuppression and recent hospitalisation [3].

Since the early 1980s, a 23-valent pneumococcal polysaccharide vaccine (PPV23) has been available and recommended in many industrialised countries for high-risk groups, including adults aged 65 years and over $[1,2]$. However, the efficacy of this vaccine remains controversial. The results of meta-analyses and clinical studies agree that there is a protective effect against IPD and pneumonia in healthy adults. However, its efficacy has not been proven in patients with risk factors for IPD $[4,5]$. Since 2005 , the vaccine has been recommended in the Region of Madrid and paid for with public funds for adults and children over the age of two years who are at high risk of disease, and for all adults aged 60 years and over.

Since 2000, conjugate pneumococcal vaccines have been available for use in young children. Following their routine use, herd immunity, an indirect effect of protection against the disease, has been observed in unvaccinated individuals [6-8]. In November 2006, the 7 -valent pneumococcal conjugate vaccine $\left(\mathrm{PCV}_{7}\right)$ was included in the childhood vaccination schedule of the Region of Madrid, using public funding. This vaccine was replaced by the 13-valent pneumococcal conjugate vaccine (PCV13) in June 2010. The mean vaccination coverage of the pneumococcal conjugate vaccines for children at two years of age from 2008 to 2011 was $94.4 \%$. In July 2012 , public funding of this vaccine was stopped due to budgetary reasons, except for people at high risk of disease. 
IPD has been a notifiable disease in the Region of Madrid since February 2007. Data are collected through a population-based epidemiological surveillance system.

This study describes the evolution of the incidence and the epidemiological characteristics of the IPD cases in people aged 60 years and over living in the Region of Madrid, and the effectiveness of PPV23 vaccine during from 2008 to 2011.

\section{Methods}

\section{Study population}

The analysis focuses on cases of IPD registered in the Surveillance System of the Region of Madrid (based on mandatory laboratory and clinical reporting), in adults aged 60 years and over, living in the Region and whose symptoms appeared between 2008 and 2011.

Individualised data were collected with a standardised questionnaire that included sociodemographic features, clinical data (date of symptom onset, clinical presentation, evolution and high-risk medical conditions), laboratory data and vaccination status. Based on the national recommendations [9], high-risk medical conditions were considered, including: immunodeficiency, cranial trauma, cranial surgery, cerebrospinal fluid leak, splenectomy, chronic liver disease, chronic heart disease, chronic kidney disease, chronic respiratory disease, cancer, HIV, diabetes mellitus and alcoholism. Only one clinical presentation and one high-risk medical condition were considered for each patient. The clinical data were obtained from attending physicians and clinical records. Vaccination status was collected by consulting the Region of Madrid's vaccination register.

\section{Laboratory methods}

An IPD case was defined as an infection with haematogenous spread of the pathogen, causing different clinical syndromes, where S. pneumoniae was identified in samples from places normally sterile by isolation, PCR or antigen detection. Serotype identification was centralised in the Madrid Regional Public Health Laboratory, and was performed by the latex agglutination test (Pneumotest-Latex, Statens Serum Institut, Copenhagen, Denmark) and the Quellung reaction.

\section{Statistical methods}

Individuals were considered to be vaccinated if date of vaccination with PPV 23 was at least 15 days before the onset of symptoms. Differences between vaccinated and unvaccinated patients were estimated. Variables associated with the disease were analysed by vaccine serotypes. Chi-squared test or Fisher's exact test were used to compare proportions.

Overall annual incidence rates were calculated per 100,000 inhabitants, as well as specific incidence rates by sex, age group, clinical presentation, and vaccine serotype. Age was coded into three age groups: $60-69,70-79$ and 80 years or older. The incidence was estimated for $\mathrm{PCV}_{7}$ serotypes $(4,6 \mathrm{~B}, 9 \mathrm{~V}, 14,18 \mathrm{C}, 19 \mathrm{~F}$ and $23 \mathrm{~F}), \mathrm{PCV}_{13}$ serotypes $(1,3,4,5,6 \mathrm{~A}, 6 \mathrm{~B}, 7 \mathrm{~F}, 9 \mathrm{~V}, 14$, $18 \mathrm{C}, 19 \mathrm{~A}, 19 \mathrm{~F}$ and $23 \mathrm{~F})$ and PPV23 serotypes (1, 2, 3, $4,5,6 \mathrm{~B}, 7 \mathrm{~F}, 8,9 \mathrm{~N}, 9 \mathrm{~V}, 10 \mathrm{~A}, 11 \mathrm{~A}, 12 \mathrm{~F}, 14,15 \mathrm{~B}, 17 \mathrm{~F}, 18 \mathrm{C}$, $19 \mathrm{~A}, 19 \mathrm{~F}, 20,22 \mathrm{~F}, 23 \mathrm{~F}$ and $33 \mathrm{~F})$. The rates were compared using relative risk (RR) and its confidence interval (Cl) at $95 \%$. The continuous census of inhabitants of the Community of Madrid was used as the reference population [10].

Vaccine effectiveness (VE) was calculated using two methods: the screening method and the indirect cohort (Broome) method. VE is interpreted as the proportion of cases prevented in vaccinated people by the effect of vaccination. Based on VE, we estimated the number of cases prevented in the study period. The screening method [11] is based on the comparison of the proportion of vaccinated cases with the proportion of the vaccinated population. The approach described by Farrington [12] was used. This allows adjustment of VE by possible confounders (sex, age group) using logistic regression models. The model requires the vaccination coverage of each of the subgroups of analysis. Data on vaccination coverage were obtained from the Region of Madrid's vaccination register.

On the other hand, the Broome method [13] is based on comparison of the vaccination odds of IPD cases due to vaccine serotypes with the vaccination odds of IPD cases due to non-vaccine serotypes, the latter serving as the control group. The VE was calculated as (1 - odds ratio) $x$ 100. VE was estimated for the group of all serotypes included in PPV23, and then for the group of serotypes that are found in PPV23, but are not found in the conjugate vaccines (that is, conjugate vaccine serotypes were excluded from the analysis). Serotypespecific VE was assessed for serotypes included in PPV 23 that had been identified in at least 30 cases. In this analysis the other PPV23 serotypes were excluded. To estimate VE by time elapsed since vaccination, vaccination status was classified as unvaccinated, vaccinated within the previous 5 years, and vaccinated more than 5 years ago. Adjustment for potential confounders (sex, age, high-risk medical condition and year of symptom onset) was made by logistic regression. Statistical significance was set at $p<0.05$. The analyses were performed using PASW Statistics, version 18.0.2 (SPSS Inc., Chicago, IL).

\section{Results}

Between 2008 and 2011, 2,432 cases of IPD were registered in the Region of Madrid, of which 864 (35.5\%) were in adults aged 60 years and over. The characteristics of IPD cases in people aged 60 years and over are shown in table 1 . A slight predominance of men was seen ( 480 cases, $55.6 \%$ ). Pneumonia and/ or empyema was the main clinical presentation (537 cases, $62.2 \%)$. A total of 368 cases $(42.6 \%)$ had received PPV23 and 519 (60.1\%) had high-risk medical 
conditions associated with pneumococcal disease. $46.8 \%$ of cases with high-risk medical conditions had been vaccinated. Immunodeficiency and/or cancer was the main high-risk medical condition (161 cases, $18.6 \%$ ), followed by chronic respiratory disease (151 cases, $17.5 \%$ ). Serotyping was available in 799 cases
(92.5\%). The main serotypes identified were the following: 3 (119 cases, $14.9 \%), 19 \mathrm{~A}$ (101 cases, $12.6 \%), 7 \mathrm{~F}$ (59 cases, $7.4 \%$ ), 1 ( 42 cases, $5.3 \%$ ) and 8 (40 cases, $5.0 \%$ ). In 588 cases (73.6\%) a serotype included in PPV 23 was identified, in 89 (11.1\%) a serotype included in PCV7 and in 431 (53.9\%) a serotype included in PCV13.

\section{TABLE 1}

Characteristics of invasive pneumococcal disease cases in patients aged 60 years and over by vaccination status, Region of Madrid, Spain, 2008-2011, $\mathrm{n}=864$

\begin{tabular}{|c|c|c|c|c|}
\hline & Total cases (\%) & Vaccinated cases (\%) & Unvaccinated cases (\%) & $\mathrm{p}$ value \\
\hline \multicolumn{5}{|l|}{ Sex } \\
\hline Men & $480(55.6)$ & $220(59.8)$ & $260(52.4)$ & $0.031^{\mathrm{a}}$ \\
\hline Women & $384(44.4)$ & $148(40.2)$ & $236(47.6)$ & $0.031^{\mathrm{a}}$ \\
\hline Total & $864(100.0)$ & $368(100.0)$ & $496(100.0)$ & \\
\hline \multicolumn{5}{|l|}{ Age } \\
\hline $60-69$ years & $266(30.8)$ & $82(22.3)$ & $184(37.1)$ & $0.000^{\mathrm{a}}$ \\
\hline 70-79 years & $285(33.0)$ & $135(36.7)$ & $150(30.2)$ & $0.046^{a}$ \\
\hline$>64$ years & $727(84.1)$ & $345(93.8)$ & $382(77.0)$ & $0.000^{\mathrm{a}}$ \\
\hline$>79$ years & $313(36.2)$ & $151(41.0)$ & $162(32.7)$ & $0.011^{\mathrm{a}}$ \\
\hline Total & $864(100.0)$ & $368(100.0)$ & $496(100.0)$ & \\
\hline \multicolumn{5}{|l|}{ Clinical presentations } \\
\hline Pneumonia/empyema & $537(62.2)$ & $223(60.6)$ & $314(63.3)$ & 0.417 \\
\hline Bacteraemia & $125(14 \cdot 5)$ & $51(13.9)$ & $74(14.9)$ & 0.661 \\
\hline Sepsis & $91(10.5)$ & $41(11.1)$ & $50(10.1)$ & 0.615 \\
\hline Meningitis & $59(6.8)$ & $28(7.6)$ & $31(6.3)$ & 0.433 \\
\hline Other & $34(3.9)$ & $19(5.2)$ & $15(3.0)$ & 0.111 \\
\hline Unknown & $18(2.1)$ & $6(1.6)$ & $12(2.4)$ & 0.422 \\
\hline Total & $864(100.0)$ & $368(100.0)$ & 496 (100.0) & \\
\hline \multicolumn{5}{|l|}{ Year } \\
\hline 2008 & $241(27.9)$ & $69(18.8)$ & $172(34.7)$ & $0.000^{\mathrm{a}}$ \\
\hline 2009 & $228(26.4)$ & $88(23.9)$ & $140(28.2)$ & 0.155 \\
\hline 2010 & $197(22.8)$ & 99 (26.9) & $98(19.8)$ & $0.013^{\mathrm{a}}$ \\
\hline 2011 & $198(22.9)$ & $112(30.4)$ & $86(17.3)$ & $0.000^{\mathrm{a}}$ \\
\hline Total & $864(100.0)$ & $368(100.0)$ & $496(100.0)$ & \\
\hline \multicolumn{5}{|l|}{ High-risk medical conditions } \\
\hline Immunodeficiency/cancer & $161(18.6)$ & $73(19.8)$ & $88(17.7)$ & 0.434 \\
\hline Chronic respiratory disease & $151(17.5)$ & $73(19.8)$ & $78(15.7)$ & 0.115 \\
\hline Chronic heart disease & $102(11.8)$ & $50(13.6)$ & $52(10.5)$ & 0.162 \\
\hline Chronic liver disease & $32(3.7)$ & $11(3.0)$ & $21(4.2)$ & 0.338 \\
\hline Chronic kidney disease & $21(2.4)$ & $9(2.4)$ & $12(2.4)$ & 0.980 \\
\hline Splenectomy & $2(0.2)$ & $1(0.3)$ & $1(0.2)$ & 0.832 \\
\hline Head injury/cranial surgery/CSF leak & $5(0.6)$ & $3(0.8)$ & $2(0.4)$ & 0.430 \\
\hline Other (diabetes, alcoholism, etc.) & $45(5.2)$ & $24(6.5)$ & $21(4.2)$ & 0.134 \\
\hline Total cases with high-risk medical conditions & $519(60.1)$ & $244(66.3)$ & $275(55.4)$ & $0.001^{\mathrm{a}}$ \\
\hline Total & $864(100.0)$ & $368(100.0)$ & $496(100.0)$ & \\
\hline Total cases serotyped & 799 (92.5) & $348(94.6)$ & $451(90.9)$ & $0.045^{a}$ \\
\hline Deaths (fatality rate) & $138(16.0)$ & $55(14.9)$ & $83(16.7)$ & 0.478 \\
\hline TOTAL & $864(100.0)$ & $368(100.0)$ & $496(100.0)$ & \\
\hline
\end{tabular}


The characteristics of cases by vaccination status are shown in Table 1. Vaccinated patients were older, had a higher proportion of men, presented more high-risk medical conditions and had a higher proportion of cases serotyped.

The proportion of PPV23 serotypes was $67.2 \%$ in vaccinated cases and $78.5 \%$ in unvaccinated cases(p<0.01). The proportion of serotypes included in PPV23 but not in conjugate vaccines was $14.7 \%$ in vaccinated and $25.5 \%$ in unvaccinated $(p<0.01)$. The proportion of $\mathrm{PCV}_{7}$ and PCV 13 serotypes was similar in vaccinated and unvaccinated patients. The serotypes with the highest difference in the proportion of vaccinated to unvaccinated cases were 6C, 16F, 19A, 14 and $24 \mathrm{~F}$ (Figure).

When we compared the disease caused by PPV23 serotypes with the disease caused by the other serotypes, the only variables that showed significant differences were vaccination status and year of symptom onset. Age, sex and presence of high-risk medical conditions showed no significant differences.

In the study period, a significant increase in the proportion of vaccinated cases $28.6 \%$ in 2008 and $56.6 \%$ in 2011) was seen, as well as in the proportion of cases with high-risk medical conditions $(47.7 \%$ in 2008 and $71.2 \%$ in 2011). The percentage of patients with highrisk medical conditions who were vaccinated ranged from $26.1 \%$ in 2008 to $60.3 \%$ in 2011 . The percentage of IPD cases caused by PPV23 serotypes has dropped ( $76.9 \%$ in 2008 and $64.0 \%$ in 2011), mainly due to the percentage of cases caused by PCV7 serotypes $(16.8 \%$ in 2008 and $6.3 \%$ in 2011).
The average annual incidence of IPD in patients aged 60 years and over from 2008 to 2011 period was 17.2 cases per 100,000 inhabitants, and incidence rose to 19.4 in patients aged 65 years and over. During this period, incidence was observed to fall by $24 \%$ (Table 2). Clinical presentations showing a significant decrease in the incidence were bacteraemia ( $42 \%$ reduction) and pneumonia/empyema (31\% reduction). The decrease was more pronounced in cases caused by vaccine serotypes, being $68 \%$ for cases by $\mathrm{PCV}_{7}$ serotypes, $34 \%$ for cases by $\mathrm{PCV}_{13}$ serotypes, and $30 \%$ for cases by PPV23 serotypes (Table 2).

The overall PPV23 uptake for people aged 60 years and over in the study period was $52.5 \%(45.8 \%$ in 2008 , $50.4 \%$ in $2009,54.6 \%$ in 2010 and $59.0 \%$ in 2011). VE estimated by the screening method is shown in Table 3. The adjusted VE by sex and age group was $68.2 \%$ (95\% Cl: 56.2-76.9) for all IPD cases and 72.8\% (95\% $\mathrm{Cl}$ : 59.1-81.8) when only the cases caused by PPV 23 serotypes were considered.

The estimated effectiveness of PPV 23 by the indirect cohort method was 44.5\% (95\% Cl: 23.8-59.6) (Table 4). VE was lower in patients aged 80 years and over $(25.5 \% ; 95 \% \mathrm{Cl}:-23.2$ to 55.0$)$ and in patients with high-risk medical conditions (31.7\%; $95 \% \mathrm{Cl}:-2.2$ to 54.4), but these differences were not significant.

In relation to VE by time since vaccination, the adjusted PPV23 effectiveness by age, sex, year of symptom onset and presence of high-risk medical conditions was $44.5 \%$ (95\% Cl: 19.4-61.8) when 5 years or fewer

\section{FIGURE}

Distribution of the main serotypes for invasive pneumococcal disease in patients aged 60 years and over, shown by vaccination status, Region of Madrid, Spain, 2008-2011, n=799




had elapsed and $32.5 \%(95 \% \mathrm{Cl}:-5.6$ to 56.9$)$ when more than 5 years had elapsed (Table 4 ).

The VE increased when considering only the serotypes that are included in PPV 23 but not found in the conjugate vaccines. This increase was slight when considering the serotypes included in PPV 23 but not in $\mathrm{PCV}_{7}$ (VE 46.8\%; 95\% Cl: 26.3-61.6), and greater when considering the serotypes included in PPV23 but not in PCV13 (VE 64.4\%; 95\% Cl: 45.2-76.8). Regarding the specific serotypes included in $\mathrm{PPV}_{23}$ that had been identified in at least 30 cases, serotypes $8,11 \mathrm{~A}, 22 \mathrm{~F}$ and $7 \mathrm{~F}$ showed the highest VE. Serotypes $14,19 A, 3$ and 1 showed no significant VE (Table 4).

Based on VE calculated by the Broome method, we estimated around 200 prevented cases of PPV23 serotypes and 100 of PPV23, non-PCV13 serotypes in this period, accounting for 7.5 and 3.7 prevented cases per 100,000 vaccinated inhabitants respectively.

Serotype 6C showed a statistically significant association with vaccination status (odds ratio (OR) 2.6; 95\% $\mathrm{Cl}: 1.4-5.0$ ) and year of symptom onset (OR 1.5; $95 \%$ $\mathrm{Cl}:$ 1.1-2.0).

\section{Discussion}

The incidence of IPD observed in our study was lower than that estimated in other countries [14-16], although it was above the European average [17]. The variability observed could be partially due to differences in the surveillance systems [18]. This incidence was also lower than that observed in other Spanish regions

\section{TABLE 3}

Vaccine effectiveness of 23-valent pneumococcal polysaccharide vaccine in patients aged 60 years and over, estimated by screening method, Region of Madrid, Spain, 2008-2011

\begin{tabular}{|l|c|c|}
\hline \multicolumn{2}{|l|}{ VE (\%) } & $95 \% \mathrm{Cl}$ \\
\hline Overall & 32.7 & $14.1-54.6$ \\
\hline Crude VE & 68.2 & $56.2-76.9$ \\
\hline VE adjusted by age and sex & 40.5 & $28.3-59.4$ \\
\hline PPV23 serotypes & 72.8 & $59.1-81.8$ \\
\hline Crude VE
\end{tabular}

PPV23: 23-valent pneumococcal polysaccharide vaccine; VE: vaccine effectiveness; $\mathrm{Cl}$ : confidence intervals

\section{TABLE 2}

Annual incidence of invasive pneumococcal disease in patients aged 60 years and over, Region of Madrid, Spain, 2008-2011, and comparison between incidence in 2011 and 2008

\begin{tabular}{|c|c|c|c|c|c|}
\hline & 2008 & 2009 & 2010 & 2011 & RR $2011 / 2008(95 \% \mathrm{Cl})$ \\
\hline Total cases & 19.99 & 15.45 & 15.21 & 15.21 & $0.76(0.63-0.92)^{\mathrm{a}}$ \\
\hline \multicolumn{6}{|l|}{ Age } \\
\hline $60-69$ & 14.27 & 12.73 & 8.76 & 10.89 & $0.76(0.55-1.06)$ \\
\hline 70-79 & 20.92 & 18.63 & 17.80 & 10.95 & $0.52(0.37-0.75)^{\mathrm{a}}$ \\
\hline$>79$ & 30.94 & 30.15 & 26.54 & 30.62 & $0.99(0.73-1.35)$ \\
\hline$>64$ & 22.34 & 20.73 & 18.04 & 16.94 & $0.76(0.62-0.93)^{a}$ \\
\hline \multicolumn{6}{|l|}{ Sex } \\
\hline Men & 24.83 & 23.51 & 23.07 & 19.48 & $0.78(0.61-1.06)$ \\
\hline Women & 16.47 & 14.59 & 9.90 & 12.10 & $0.73(0.56-0.97)^{\mathrm{a}}$ \\
\hline \multicolumn{6}{|l|}{ Clinical presentations } \\
\hline Pneumonia/empyema & 12.19 & 11.67 & 10.67 & 8.38 & $0.69(0.54-0.88)^{a}$ \\
\hline Bacteraemia & 3.73 & 2.33 & 1.80 & 2.15 & $0.58(0.36-0.92)^{\mathrm{a}}$ \\
\hline Sepsis & 1.49 & 1.93 & 1.65 & 2.15 & $1.44(0.80-2.61)$ \\
\hline Meningitis & 1.16 & 1.45 & 0.71 & 1.38 & $1.19(0.59-2.40)$ \\
\hline Other & 0.75 & 0.48 & 0.55 & 0.92 & $1.24(0.52-2.93)$ \\
\hline \multicolumn{6}{|l|}{ Vaccine serotypes } \\
\hline Serotypes $\mathrm{PCV}_{7}$ & 2.90 & 2.25 & 1.10 & 0.92 & $0.32(0.16-0.61)^{\mathrm{a}}$ \\
\hline Serotypes PCV13 & 9.54 & 10.38 & 8.24 & 6.30 & $0.66(0.50-0.88)^{a}$ \\
\hline Serotypes $\mathrm{PCV}_{13}$-non $\mathrm{PCV}_{7}$ & 6.64 & 8.13 & 7.14 & 5.38 & $0.81(0.59-1.12)$ \\
\hline Serotypes PPV23 & 13.27 & 13.76 & 10.67 & 9.30 & $0.70(0.55-0.89)^{\mathrm{a}}$ \\
\hline Serotypes PPV23-non PCV7 & 10.37 & 11.51 & 9.57 & 8.38 & $0.81(0.62-1.04)$ \\
\hline Serotypes PPV23-non PCV13 & 3.90 & 3.62 & 2.59 & 3.15 & $0.81(0.53-1.23)$ \\
\hline
\end{tabular}


where pneumococcal vaccination is not included in the childhood immunisation schedule [19-22].

Some factors such as PCV uptake, blood culture practice, fluctuations of serotype prevalence over time and antimicrobial use may play a role in the epidemiological changes observed in IPD among adults. No important changes in these factors could be detected in the four years included in the study. The main change observed was the introduction of $\mathrm{PCV}_{13}$ in children in June 2010, which may explain the decrease of PCV13, non-PCV7 serotypes after 2010.

PPV23 vaccination shows an effect on incidence of the disease, since there is a reduction in the incidence of cases due to the serotypes included in PPV23, in accordance with the increase in PPV23 uptake. The highest reduction in incidence was for serotypes included in $\mathrm{PCV}_{7}$. This agrees with a herd immunity effect due to this vaccine [6-8] and suggests a higher impact due to the indirect effect of vaccination in children rather than by the direct effect of vaccination in people aged 60 years and older.

The VE obtained by the Broome method (44.5\%) was similar to that estimated in England and Wales (48\%) [23]. Adjusted VE by screening method (68.2\%) was also comparable to VE seen in Australia (71\%) [24],
Scotland (61.7\%) [25] and Catalonia (70\%) [26]. VE in preventing vaccine-type IPD obtained by the screening method was greater than overall VE, with an adjusted VE of $72.8 \%$. This agrees with the VE observed in other studies $[26,27]$.

The differences observed in VE by age, high-risk medical condition, serotype and time since vaccination in our study are similar to those described previously $[23,26,27]$, but were not significant because the point estimate had very wide confidence intervals. Observational studies of VE against IPD usually present lower power to stratify for these variables.

Differences in the VE estimated have been found according to the method applied [24,25]. In our study the adjusted VE by the screening method was higher than the estimations using the Broome method. These results were similar to estimates in Scotland $(61.7 \%$ vs $51 \%$ ) [25] and this could be due to the fact that the Broome method also uses IPD cases as a control group.

The VE observed for the disease caused by the serotypes included in PPV23 but not in the conjugate vaccines is higher than that observed for all serotypes of PPV23. This result could be due to the high prevalence in the population of serotypes common to PCV13 and PPV23 vaccines, associated with the serotype

TABLE 4

Vaccine effectiveness of 23-valent pneumococcal polysaccharide vaccine in patients aged 60 years and over, estimated by the indirect cohort method, Region of Madrid, Spain, 2008-2011

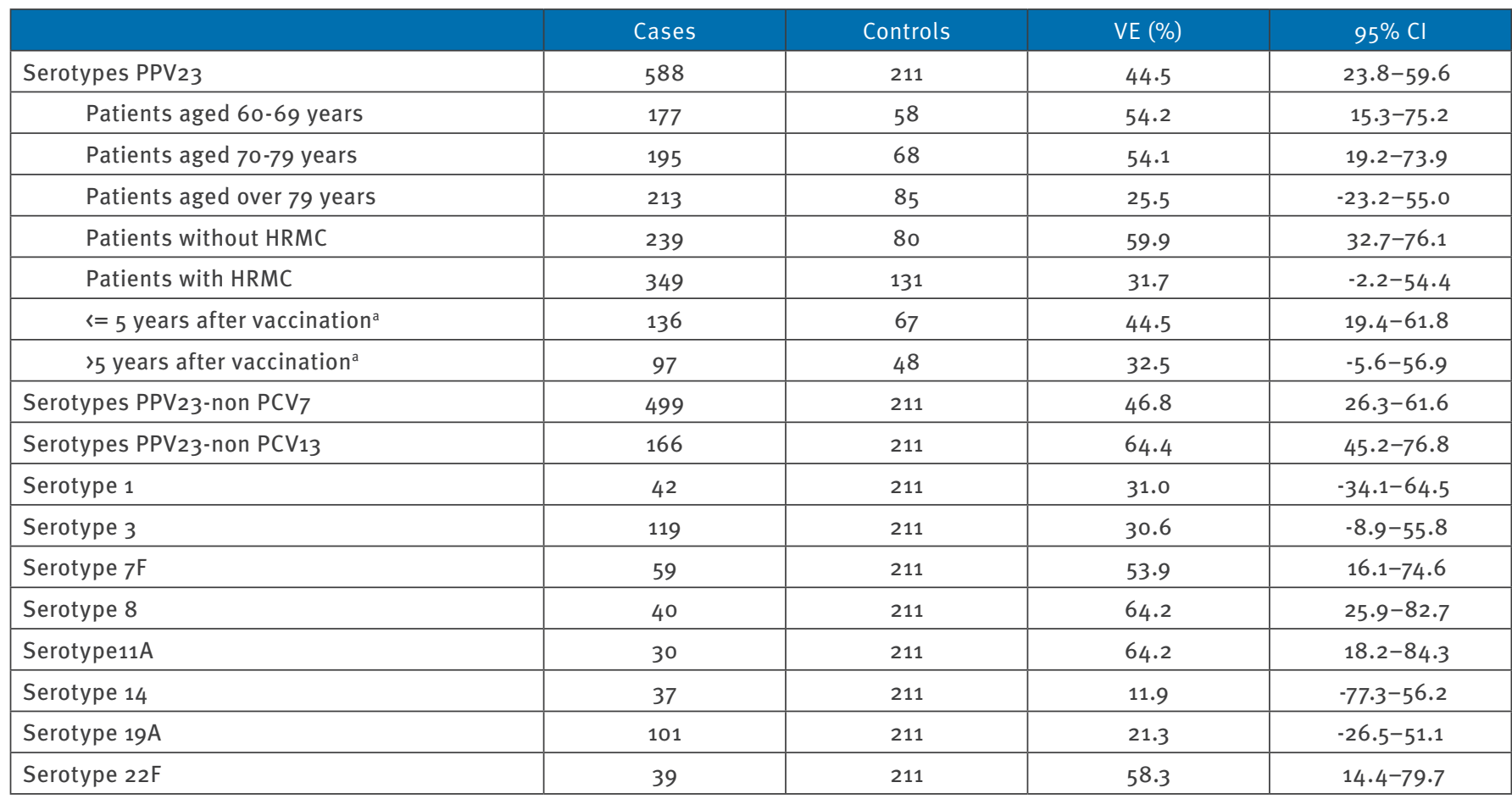

PPV23: 23-valent pneumococcal polysaccharide vaccine; VE: vaccine effectiveness; CI: confidence intervals; HRMC: high-risk medical conditions; PCV7: 7-valent pneumococcal conjugate vaccine; PCV13: 13-valent pneumococcal conjugate vaccine.

a Adjusted by sex, age, HRMC and years of symptoms onset 
replacement described after the routine use of $\mathrm{PCV}_{7}$ $[8,28,29]$, and with the differential effectiveness by serotype, identified in other studies [23]. This would suggest that PPV23 vaccine has a reduced effectiveness in populations using the conjugate vaccine in the childhood immunisation schedule.

The higher VE observed for serotypes 8, 11A, 22F and $7 \mathrm{~F}$ could be related to differences in vaccine response of the specific serotypes. A higher VE for serotype $7 \mathrm{~F}$ and lower for serotypes 1 and 3 have also been observed in the study performed in England and Wales [23].

Each method has both advantages and disadvantages. The screening method is quick and simple, but it requires accurate data on vaccination coverage and vaccination status of cases [30]. In our study these data were taken from the Region of Madrid's vaccine register, which collects nominal data. The screening method allows the overall effectiveness to be estimated and is very useful for routine monitoring. However it does not allow certain risk factors to be taken into account due to the non-availability of vaccination coverage in specific groups of population [12].

The Broome method can be used on specific groups of patients, such as those who show risk factors. However, it does not allow the effectiveness for the global disease to be estimated, since the cases due to non-vaccine serotypes are used as the control group. Due to the high proportion of cases with identified serotypes (92.5\%), there is no need to make any assumptions in cases with unknown serotype, avoiding any possible bias related to them. The high proportion of cases with identified serotype and the independence between data on serotype and vaccination status would exclude an important bias in the estimation of VE. This method has shown its usefulness when applied to surveillance data for this disease, showing results similar to those obtained using case-control studies [23,31,32].

The higher proportion of disease due to serotype 6C in vaccinated patients observed in our study could be due to the replacement of serotypes. There has been an increase in disease due to this serotype following the routine use of $\mathrm{PCV}_{7}$ both in carriers [33] and in cases with invasive disease [34].

One of the strengths of our study is that although it is observational and based on surveillance data, it is limited to four recent years, thus important changes in the notification, diagnosis and serotyping of cases can be ruled out.

Vaccine efficacy of PPV23 against IPD has been established in clinical trials, but in high-risk patients it has not been possible to demonstrate protection $[4,5]$. Observational studies have shown significant vaccine effectiveness [23-26]. PPV23 is recommended in many countries for people with high-risk medical conditions and in some countries for universal vaccination of the elderly. In England and Wales, Andrews et al. observed evidence of individual protection against PPV23 serotypes despite lack of impact on IPD incidence at the population level [23] and the UK's Joint Committee on Vaccination and Immunisation recommended continuation of PPV 23 vaccination programmes for all healthy individuals aged 65 years and over [35]. Several studies of cost-effectiveness of pneumococcal vaccination in the elderly have been published [36-38] and some of them have concluded that universal programmes are more cost-effective than selective vaccination of highrisk groups $[36,38]$.

The use of PCV13 has recently been approved for people aged 50 years and over. However, its effectiveness in preventing pneumonia and IPD has not yet been proven in clinical trials [39]. Thus, at present different institutions consider that the evidence available is insufficient to recommend the routine use of $\mathrm{PCV}_{13}$ in adults $[1,40,41]$. This vaccine has been recently recommended for use in adults with high-risk medical conditions [40].

In conclusion, our study shows that PPV23 is effective in preventing IPD in patients aged 60 years and older, with a higher VE in patients without high-risk medical conditions. These results are compatible with the current recommendation of PPV23. Efforts to improve PPV23 uptake should continue. Epidemiological surveillance should be continued in order to evaluate the impact on IPD incidence in adults and elderly of the indirect effects of vaccinating children with pneumococcal conjugate vaccines and the role of PCV13 in adults with high-risk medical conditions.

\section{Acknowledgements}

We are grateful to the public health professionals of the Madrid Surveillance Network and the Public Health Regional Laboratory, as well as the physicians who participated in the surveillance of this disease. We also thank Dulce López-Gay for her contribution to the statistical analysis.

\section{Conflict of interest}

MA Ordobás, MA Gutiérrez, A Arce and JC Sanz have received funding from Pfizer to attend scientific meetings. L Garcia Comas has received funding from Pfizer and Sanofi to attend scientific meetings.

\section{Authors' contributions}

MA Gutiérrez Rodríguez and MA Ordobás Gavín designed the study. E Córdoba Deorador, MD Lasheras Carbajo, JA Taveira Jiménez and F Martín Martínez made the acquisition and recording of data. D Iniesta Fornies oversaw vaccination coverage data of the Vaccination Register. JC Sanz Moreno was the microbiologist who performed the laboratory analysis. MA Gutiérrez Rodríguez, MA Ordobás Gavín, L García Comas and A Arce Arnaez reviewed the analysis and the results. MA Gutiérrez Rodríguez wrote the manuscript. All authors reviewed the manuscript and agree with results and conclusions. The final version was approved by all authors. 


\section{References}

1. Pneumococcal vaccines, WHO position paper-2012. Weekly epidemiological record. 2012;87(14):129-44.

2. 23-valent pneumococcal polysaccharide vaccine. WHO position paper. Weekly epidemiological record. 2008; 83(42):373-84.

3. Musher DM. Streptococcus pneumoniae. In: Mandell, Douglas, Bennett, editors. Enfermedades infecciosas. Principios y práctica. 2nd ed. Elsevier España SA:Madrid; 2006.

4. Moberley S1, Holden J, Tatham DP, Andrews RM. Vaccines for preventing pneumococcal infection in adults. Cochrane Database Syst Rev. 2013;1:CDo00422.

5. Huss A, Scott P, Stuck AE, Trotter C, Egger M. Efficacy of pneumococcal vaccination in adults: a meta-analysis. CMAJ. 2009;180(1):48-58. http://dx.doi.org/10.1503/cmaj.080734

6. Direct and indirect effects of routine vaccination of children with 7-valent pneumococcal conjugate vaccine on incidence of invasive pneumococcal disease-United States, 1998-2003. MMWR Morb Mortal Wkly Rep. 2005;54(36):893-7.

7. Whitney CG, Farley MM, Hadler J, Harrison LH, Bennett NM, Lynfield $R$ et al. Decline in invasive pneumococcal disease after the introduction of protein-polysaccharide conjugate vaccine. N Engl J Med. 2003;348(18):1737-46. http://dx.doi.org/10.1056/ NEJMoa022823

8. Miller E, Andrews NJ, Waight PA, Slack MPE, George RC. Herd immunity and serotype replacement 4 years after seven-valent pneumococcal conjugate vaccination in England and Wales: an observational cohort study. Lancet Infect Dis. 2011;11(10):7608. http://dx.doi.org/10.1016/S1473-3099(11)70090-1

9. Vacuna de neumococo. Vacunación en adultos. Recomendaciones. Madrid: Subdirección General de Promoción de la Salud y Epidemiología: Ministerio de Sanidad y Consumo; 2004. [Accessed June 2013]. Available from: http://www.msssi. gob.es/ciudadanos/proteccionSalud/vacunaciones/docs/ recoVacunasAdultos.pdf

10. Estadística de Población de la Comunidad de Madrid. Características demográficas básicas. [Accessed June 2013]. Available from: http://www.madrid.org/iestadis/fijas/estructu/ demograficas/padron/estructupcrd.htm

11. Orestein WA, Bernier RH, Dondero TJ, Hinman AR, Marks JS, Bart KJ et al. Field evaluation of vaccine efficacy. Bull World Health Organ. 1985;63(6):1055-68.

12. Farrington CP. Estimation of vaccine effectiveness using the screening method. Int J Epidemiol. 1993;22:742-6. http:// dx.doi.org/10.1093/ije/22.4.742

13. Broome CV, Facklam RR, and Fraser DW. Pneumocococcal disease after pneumococcal vaccination: an alternative method to estimate the efficacy of pneumococcal vaccine. $\mathrm{N}$ Engl J Med. 1980;303(10):549-52. http://dx.doi.org/10.1056/ NEJM198009043031003

14. Pilishvili T, Lexau C, Farley MM, Hadler J, Harrison LH, Bennett NM et al. Sustained reductions in invasive pneumococcal disease in the era of conjugate vaccine. J Infect Dis. 2010;201(1):32-41. http://dx.doi.org/10.1086/648593

15. Active Bacterial Core Surveillance Report (ABCs), Emerging Infections Program Network. Streptococcus pneumoniae, 2011. Atlanta: Centre for Disease Control and Prevention (CDC); 2013. [Accessed June 2013]. Available from: http://www.cdc.gov/ abcs/reports-findings/survreports/spneu11.pdf

16. Ingels H, Rasmussen J, Andersen PH, Harboe ZB, Glismann S, Konradsen $\mathrm{H}$, et al. Impact of pneumococcal vaccination in Denmark during the first 3 years after PCV introduction in the childhood immunization programme. Vaccine. 2012;30(26):3944-50. http://dx.doi.org/10.1016/j. vaccine.2012.03.060

17. European Centre for Disease Prevention and Control (ECDC). Surveillance of invasive pneumococcal disease in Europe, 2010. Stockholm: ECDC; 2012. [Accessed June 2013]. Available from: http://www.ecdc.europa.eu/en/ publications/Publications/invasive-pneumoccocal-diseasesurveillance-2010.pdf

18. Hanquet G, Perrocheau A, Kissling E, Bruhl DL, Tarragó D, Stuart J et al. Surveillance of invasive pneumococcal disease in 30 EU countries: towards a European system? Vaccine. 2010;28(23):3920-8. http://dx.doi.org/10.1016/j. vaccine.2010.03.069

19. Guevara M, Barricarte A, Gil-Setas A, Garcia-Irure JJ, Beristain $X$, Torroba $L$ et al. Changing epidemiology of invasive pneumococcal disease following increased coverage with the heptavalent conjugate vaccine in Navarre, Spain. Clin Microbiol Infect. 2009;15(11):1013-9. http://dx.doi. org/10.1111/j.1469-0691.2009.02904.x

20. Ardanuy C, Tubau F, Pallares R, Calatayud L, Domínguez MA, Rolo D et al.. Epidemiology of invasive pneumococcal disease among adult patients in Barcelona before and after pediatric 7-valent pneumococcal conjugate vaccine introduction,
1997-2007. Clin Infect Dis. 2009;48(1):57-64. http://dx.doi. org/10.1086/594125

21. Ochoa-Gondar O, Vila-Corcoles A. Incidence of invasive pneumococcal disease among elderly people in Southern Catalonia, Spain, 2002-2009: an increase in serotypes not contained in the heptavalent conjugate vaccine. J Infect. 2011;63(6):434-40. http://dx.doi.org/10.1016/j.jinf.2011.08.013

22. Mu-oz-Almagro C, Ciruela P, Esteva C, Marco F, Navarro M, Bartolome R et al. Serotypes and clones causing invasive pneumococcal disease before the use of new conjugate vaccines in Catalonia, Spain. J Infect. 2011;63(2):151-62. http:// dx.doi.org/10.1016/j.jinf.2011.06.002

23. Andrews NJ, Waight PA, George RC, Slack ME, Miller E. Impact and effectiveness of 23-valent pneumococcal polysaccharide vaccine against invasive pneumococcal disease in the elderly in England and Wales. Vaccine. 2012;30(48):6802-8. http:// dx.doi.org/10.1016/j.vaccine.2012.09.019

24. Andrews RM, Counahan ML, Hogg GG, Mclntyre PB. Effectiveness of a publicly funded pneumococcal vaccination program against invasive pneumococcal disease among the elderly in Victoria, Australia. Vaccine. 2004;23(2):132-8. http:// dx.doi.org/10.1016/j.vaccine.2004.06.016

25. Mooney JD, Weir A, McMenamin J, Ritchie LD, Macfarlane TV, Simpson CR, et al. The impact and effectiveness of pneumococcal vaccination in Scotland for those aged 65 and over during winter 2003/2004. BMC Infect Dis. 2008;8:53. http://dx.doi.org/10.1186/1471-2334-8-53

26. Dominguez A, Salleras L, Fedson DS, Izquierdo C, Ruiz L, Ciruela $P$, et al. Effectiveness of pneumococcal vaccination for elderly people in Catalonia, Spain: a case-control study. Clin Infect Dis. 2005; 40(9):1250-7. http://dx.doi. org/10.1086/429236

27. Vila-Corcoles A, Ochoa-Gondar O, Rodríguez-Blanco T, Gutiérrez-Pérez A, Vila-Rovira A, Group ES. Clinical effectiveness of 23-valent pneumococcal polysaccharide vaccine against pneumonia in patients with chronic pulmonary diseases: A matched case-control study. Hum Vaccin Immunother. 2012;8(5):639-44. http://dx.doi.org/10.4161/ hv.19466

28. Weinberger DM, Malley R, Lipsitch M. Serotype replacement in disease after pneumococcal vaccination. Lancet. 2011;378(9807):1962-73. http://dx.doi.org/10.1016/ So140-6736(10)62225-8

29. Changing epidemiology of pneumococcal serotypes after introduction of conjugate vaccine: July 2010 report. Wkly Epidemiol Rec. 2010;85(43):434-6.

30. Hatton P. The use of screening technique as a method of rapidly estimating vaccine efficacy. Public Health. 1990;104(1):21-5. http://dx.doi.org/10.1016/ So033-3506(05)80341-5

31. Miller E, Andrews NJ, Waight PA, Slack MPE, George $\mathrm{RC}$. Effectiveness of the new serotypes in the 13-valent pneumococcal vaccine. Vaccine. 2011;29(49):9127-31. http:// dx.doi.org/10.1016/j.vaccine.2011.09.112

32. De Serres G, Pilishvili T, Link-Gelles R, Reingold A, Gershman $K$, Petit $S$ et al. Use of surveillance data to estimate the effectiveness of the 7-valent conjugate pneumococcal vaccine in children less than 5 years of age over a 9 year period. Vaccine. 2012;30(27):4067-72. http://dx.doi.org/10.1016/j. vaccine.2012.04.017

33. Tocheva AS, Jefferies JMC, Rubery H, Bennett J, Afimeke $G$, Garland J et al. Declining serotype coverage of new pneumococcal conjugate vaccines relating to the carriage of Streptococcus pneumoniae in young children. Vaccine. 2011;29(26):4400-4. http://dx.doi.org/10.1016/j. vaccine.2011.04.004

34. Rolo D, Fenoll A, Ardanuy C, Calatayud L, Cubero M, de la Campa AG et al. Trends of invasive serotype 6C pneumococci in Spain: emergence of a new lineage. J Antimicrob Chemother. 2011;66(8):1712-8. http://dx.doi.org/10.1093/jac/dkr193

35. Joint Committee on Vaccination and Immunisation (JCVI) JCVI statement on the routine pneumococcal vaccination programme for adults aged 65 years and older. London: JCVI; 20 July 2011. [Accessed September 2014]. Available from: http://webarchive.nationalarchives.gov.uk/20130107105354/ http://www.dh.gov.uk/ab/JCVI/DH_094744

36. Melegaro A, Edmunds WJ. The 23-valent pneumococcal polysaccharide vaccine. Part II- a cost-effectiveness analysis for invasive disease in the elderly in England and Wales. Eur J Epidemiol. 2004;19:365-75. http://dx.doi.org/10.1023/ B:EJEP.0000024752.48929.bd

37. Evers SM, Ament AJ, Colombo GL, Konradsen HB, Reinert RR, Sauerland D et al. Cost-effectiveness of pneumococcal vaccination for prevention of invasive pneumococcal disease in the elderly: an update for 10 Western European countries. Eur J 
Clin Microbiol Dis. 2007;23:531-40. http://dx.doi.org/10.1007/ S10096-007-0327-z

38. Smith KJ, Zimmerman RK, Lin Ch J, Nowalk MP, Ko F, McEllistrem MC et al. Alternative strategies for adult pneumococcal polysaccharide vaccination: A costeffectiveness analysis. Vaccine. 2008;26(11):1420-31. http:// dx.doi.org/10.1016/j.vaccine.2008.01.007

39. Hak E, Grobbee DE, Sanders EAM, Verheij TJM, Bolkenbaas $M$, Huijts SM et al. Rationale and design of CAPITA: a RCT of 13-valent conjugated pneumococcal vaccine efficacy among older adults. Neth J Med. 2008;66(9):378-83.

40. Centers for Disease Control and Prevention (CDC). Licensure of 13-valent pneumococcal conjugate vaccine for adults age 50 years and older. MMWR Morb Mortal Wkly Rep. 2012;61(21):394-5.

41. Joint Committee on Vaccination and Immunisation (JCVI). JCV statement on discontinuation of the routine pneumococcal vaccination programme for adults aged 65 years and older. London: JCVI; 16 March 2011. [Accessed September 2014] Available from: http://webarchive.nationalarchives.gov. uk/20130107105354/http://www.dh.gov.uk/prod consum dh/ groups/dh_digitalassets/@dh/@ab/documents/digitalasset/ dh_125122.pdf 